\title{
Study on the Moderate Diversification of Industrial Structure in Macao
}

\author{
Pingping Lu \\ School of Economics, Jinan University, Guangzhou, China \\ Email: 1144895930@qq.com
}

Received 19 January 2016; accepted 26 February 2016; published 29 February 2016

Copyright (C) 2016 by author and Scientific Research Publishing Inc.

This work is licensed under the Creative Commons Attribution International License (CC BY). http://creativecommons.org/licenses/by/4.0/

(c) (7) Open Access

\begin{abstract}
As a result of past economic growth and the foundation of future economic growth, industrial structure has become an important factor for economic growth. This article, based on the existing moderate diversification research results of Macao industrial structure, researches Macau industry output gap by industry Gini coefficient, measures Macau deformity of the existing industrial structure, and analyzes the necessity of the moderate diversification of Macau industrial structure. At last, it gives some suggestions about the moderate diversified industry.
\end{abstract}

\section{Keywords}

Industrial Structure, Industry Gini Coefficient, Moderate Diversification, Industrial Output Gap, Gambling Industry

\section{Introduction}

According to the data which were published by Macao Gambling Industry Supervision and Coordination Bureau on March 3, 2015, it was shown that Macao gambling revenue fell for nine consecutive months since 2014; gambling revenue had an unprecedented underground fall by $48.6 \%$ in February to \$19.5 billion; Macau’s gambling does not have the past glory. Because of the depression of the gambling industry, Macau's GDP in the third quarter of 2014 had negative growth for the first time in five years (compared to the same period last year); the GDP growth rate was also recorded negatively $24.5 \%$ in the first quarter of 2015 . Macao's economy has been a severe trauma, and it has become the worst economy in the world, so gambling industry has become the culprit to contain the economy of Macao. However, it is the best time to recognize and examine the existing growth model and the crux of the dilemma of economic diversification, to stipulate the development direction of economic and the implementation path of economic diversification, and to develop a comprehensive breakthrough strategy when Macao is facing the worst economic downturn moment. In the speech of the 15th anni- 
versary of the Macau return celebration, Xi Jinping proposed to strengthen and improve the supervision of the gambling industry in Macao, actively cultivate new economic growth point, and then promote the economic sustainable development in Macao. Therefore, Macao economic and industrial structure moderate diversification is not only the key methods to resolve the crisis of economic downturn, but also the necessary way to the sustainable development of Macao economy.

\section{Research Summary of Macao Industry Moderate Diversification}

The research on the moderate diversification of the industrial structure in Macao was mainly based on the following four aspects. First, some scholars analyzed the connotation of the moderate diversification: Xu Yamin argues that "moderate pluralism" means not a dominant gambling industry to support the Macau economy. But there are several pillar industries coexist in the entire industrial structure, they share in the total is not equal, but they must be associated with each other and coordinated development [1]. Secondly, some scholars analyzed the necessity of moderate diversification development: Lian-cun Zuo, Liu Jing proposed that Macao's tertiary industry although developed well, but excessive depended on gambling industry, it determine the Macao economy lack of ability to resist risk, so they put forward to actively promote the moderate diversification of Macao's economy [2]. Chen En, Gui Liang Huang based on Characteristics of the industrial structure in Macao, then analyzing the path of the industrial moderate diversification in Macao and discussing the necessity of the moderate diversification from the aspects of the control of the development scale of the gambling industry and developed comprehensive tourism which gambling industry play a leading role [3]. Thirdly, some scholars analyzed the orientation of the moderately diversified development of Macao industry: Guo Xiaodong, Liu Changsheng proposed should be based on the existing industrial structure to prompt Macao gradually take the path of moderate diversification [4]. Zheng Huafeng points out that gambling industry should seek breakthrough in the field of sustainable development from the perspective of game theory, then truly optimizing the industrial structure and achieving moderate economic diversification [5]. Chi Ping Yuan, Liang Wen proposed that the Macao industrial cooperation with Hengqin is undoubtedly for the sustainable development of Macao to break the shackles. The Macau government should make full use of Macau and Hengqin cooperation, promoting the sustainable development of Macao's economy and supporting the diversified development of Macao industry [6]. Fourthly, some scholars analyzed the measures for the development of moderate diversification: Professor Feng Xiaoyun thinks that Macau's "Expand Bibcock" and moderately "Synergetic Development" strategies are two parallel strategies which are indispensable and cannot be neglected for the development of Macao economy [7]. Feng Bangyan believes that long, medium and short-term policy can optimize labor force, short can enter foreign labor, medium can introduce professional, long can develop education [8]. Chen Xiang shows that the development of Macao's gambling industry almost reached the limit and boundaries of the economic diversification requirements by studying Macao land bearing state. Therefore, on the basis of monitoring and controlling the development of gambling industry and doing a good job in Macao planning and with the aid of land and human resources cooperation in economic integration of Guangdong, Hong Kong and Macao, it is an effective way to promote the moderate diversification of Macao by seeking a good position, expanding the investment field and initiatively choosing the leading industry [9].

The existing research is very comprehensive and in-depth. It can provide some guidance and help for the industrial diversification in Macao. But the existing literature basically stays on the qualitative analysis, there is still a big gap in the quantitative and empirical analysis, fewer scholars analyze the deformity development problems of Macao industrial from empirical aspect. In view of this, this paper will study the degree of deformity of the industrial structure in Macao and systematically explore the path and direction of the industrial diversification of Macao by using the industrial Gini coefficient, in order to guide the Macao draft moderate diversification policy effectively.

\section{The Output Gap Empirical Analysis of Industrial Structure}

\subsection{Industry Gini Coefficient}

The Gini coefficient was proposed by Italy economist Gini Corrido at 1912, using to measure income inequality. The Gini coefficient not only can be used to measure the income gap between the residents, but also can be used to measure the income gap between the region and the industry. Xing Jian Hong [10], Gao Yuan [11] adopted 
Gini coefficient decomposition model to analyze China's income gap between the industry, and analyzing the income gap between different industries of our country by empirical method from different angles. With the development of economy, the Gini coefficient has been widely used to measure differences in various economic and social indicators. As one of the essential variables in solving the Gini coefficient, especially the analysis of the income gap between the industry, precise industry revenue data is very important to the empirical analysis result, and the income is closely related to the gross national product GDP, it can be seen that GDP is the real important variables which influenced the Gini coefficient results. Therefore, this paper based upon the method of industry income gap Gini coefficient of Gao Yuan, using industrial output value instead of industry income to obtain industry Gini coefficient and analyzing the gap between industrial output value, to study the development and adjustment of the industrial structure of the economy.

Industry Gini coefficient is an index of evaluating imbalanced distribution in resources (labor, capital, policy, etc.), industrial output gap and the deformity of industrial structure development. In general, Gini coefficient regards 0.4 as the "warning line" of income gap, if the Gini coefficient exceeds 0.4 ; it means that the income gap is too large and uneven distribution of wealth, so it may cause a lot of social problems. With the development of economy, the Gini coefficient is widely used to measure the difference of economic index. It not only limited to measure the income gap between the residents, but also can be used to measure the income gap between urban and rural areas. At this point, 0.4 can be defined as the "differential boundary", and as the boundary of economic indicator difference degree. In this paper, the Gini coefficient is used to measure the output gap between different industries in Macao, and industry Gini coefficient simulate the algorithm of Gini coefficient, so 0.4 can be as a "warning line" of output gap. It indicates that the industry output gap in Macau is small and industrial structure is reasonable if industrial Gini coefficient is lower than 0.4; it indicates that the industry output gap in Macau is lager and industrial structure is not reasonable if industrial Gini coefficient is more than 0.4. This paper first put forward the concept of industry Gini coefficient and uses industrial Gini coefficient to measure the degree of deformity of industrial structure in Macao, then the author analyses the necessity of industry moderate diversification in Macao.

\subsection{Industry Gini Coefficient Formulas}

We can obtain the Gini coefficient according to the definition of Lorenz curve, expressions such as:

$$
\text { Gini }=\frac{\left[\frac{1}{2}-\int_{0}^{1} L(x) \mathrm{d} x\right]}{\frac{1}{2}}=1-2 \int_{0}^{1} L(x) \mathrm{d} x=2 \int_{0}^{1}[x-L(x)] \mathrm{d} x
$$

$L(x)$ is the expression of the Lorenz curve, we can find out the Gini coefficient by the definition of Lorenz curve. Because this article analyzes industry output gap by thirteen industry data, it is more than two sets of data. So it is more accurate to use another formula to solve the industry Gini coefficient. And it can be relatively simple to calculate the industry Gini coefficient from multiple sets of data by Matlab. Therefore this paper industry Gini coefficient formula is:

$$
\mathrm{G}=\frac{1}{2 n^{2} u} \sum_{i} \sum_{j}\left|y_{i}-y_{j}\right|
$$

$N$ represents the number of industrial categories in (2); $U$ represents the average output value of all industries; $Y_{i}$ and $Y_{j}$ respectively represent the output value of $i$ and $j$ industries. We can see that the formula of (2) is accorded with the actual situation and can better reflect the industrial output gap. So this paper solves the Gini coefficient of Macao industry by formula (2), and combines with the leading industry theory and unbalanced development theory to analyze the degree of deformity of industrial structure in Macao.

\subsection{Analysis on the Degree of Deformity of Industrial Structure in Macao}

1) The Industry Gini Coefficient Analysis

This article uses Matlab to solve industry Gini coefficient from 2001-2012 industrial production data, the results such as Table 1 : 
Table 1. Macao industrial Gini coefficient in 2001-2012.

\begin{tabular}{llllllllllll}
\hline 2001 & 2002 & 2003 & 2004 & 2005 & 2006 & 2007 & 2008 & 2009 & 2010 & 2011 & 2012 \\
\hline 0.398 & 0.398 & 0.410 & 0.421 & 0.429 & 0.440 & 0.480 & 0.477 & 0.475 & 0.540 & 0.569 & 0.579 \\
\hline
\end{tabular}

Data Description: the result calculated according to the "Macao Statistical Yearbook” (2002-2013).

The results of the data in Table 1 shows that the Macao industry Gini coefficient continues to increase, and more and more far away from 0.4 , which shows that the growing gap between the industry in Macao, at the same time means that the formation of the leading industry. Since 2001, Macau has gradually formed the industrial structure which the gambling industry is the leading industries, so the gambling industry became the main source of fiscal revenue in Macau. However, the gambling industry lacks the characteristics of "embeddedness" and "correlation effect", and cannot promote the economic sustainable development. From this we can know that the gambling industry as the leading industry of the industrial structure will not be conducive to the sustainable development of Macao economy. Secondly, from the industry's Gini coefficient, we can know that the gambling industry has attracted a large number input of labor, capital and material since the implementation of the policy of "opening up", then seriously occupied other industry resources and shown a "blowout" development, formed "one industry alone" abnormal industrial structure at last. The Macao industry Gini coefficient was as high as 0.579 in 2012; the disparity between the industry output gaps is very big, so the deformity degree of industrial structure in Macao is grim.

\section{2) Analysis of Leading Industry Theory}

The first scholars to put forward the theory of leading industry is the American economist Walt Whitman Rostow, he put forward the strong diffusion effect, new production function, high speed growth of productivity were three essential conditions of the leading industry. He also put forward the choice benchmark of leading industry-Rostow benchmark in his book "Leading department and take off", advocating to choose an industry which has strong diffusion effect (prospective, retrospective, side) as the leading industry, and promoting the upgrading of the whole industrial structure and the development of regional economy by Leading industry's advantages.

According to Rostow's leading industry theory, only accorded with the requirements of the leading industries could promote the healthy development of the economy. But the situation of leading industry in Macao is entirely different with this theory; gambling industry as Macau's leading industry, it rooted in foreign capital, not the native resources; therefore, gambling industry lacks of the support of high and new technology and no strong diffusion effect; The driving effect of gambling industry to other industries which rooted in local resources is small and small, on the contrary, it occupied the market and development space of other industry. It is thus clear that gambling industry cannot exert the effectiveness of leading industry; the industrial structure of "one industry alone" is inconsistent with the strategic orientation of Macao's sustainable development.

\section{3) Analysis of Unbalanced Growth Theory}

Looking from the pattern of economic growth, the theory of economic growth includes balanced growth theory and unbalanced growth theory. In 1958, the unbalanced growth theory was put forward by American economist Hirschman in the book "economic development strategy". Hirschman believes that the most effective way of economic growth is the priority to implement the strategy of unbalanced growth; especially in the developing countries with limited resources is more suitable for taking unbalanced growth strategy to enhance their competitiveness. According to the principle of "maximizing decision making", Hirschman believes that the industries which have the largest correlation effect in national economy structure should be the industry which be priority to develop in the developing countries. He believes that put the limited resources into the big "association effect" industry, and transferring to other industries through the association effect mechanism; its effectiveness will be greater than the small "association effect" industry and to use resources maximum, thereby promoting economic growth and obtaining an effective competitive.

Macao is a micro economy, which land area only have 32.8 square kilometers, it not only the scarcity of land resources, other material resources are also very scarce. So it is the inevitable choice for the economic development of Macao to develop leading Industry by using limited resources, so the development of the gaming industry is a common cause of internal and external factors. However, gambling industry which is non rooted lacks of "correlation effect" and lacks of positive effect on other industries in Macao, which does not conform to the un- 
balanced growth strategy; therefore, Macao needs to reconstruct the big "association effect" industry, combining with the unbalanced growth strategy to use limited resources rationally, and to achieve the economic growth in Macao by the big "association effect” industry.

\section{The Necessity of the Moderate Diversification of Industrial Structure in Macao}

\subsection{Gambling Monopoly Competition Firmly Fixed Position}

In 2003, the "free walker" policy which practiced in China brings a large number of passengers for Macao and inbound passengers continued to increase. Passengers amounted to 31,525,632 people in 2014, and in which the individual tour visitors reached 19,191,548 people (up to 60.88\%), China has become the largest source of Macao gambling industry and Macau's gambling revenue is increasing. As shown in Table 2, gambling revenue increased by 30315 million Macao dollars to 361866 million Macao dollars from 2003 to 2013, gambling revenue growth 11.94 times than 11 years ago with an average annual growth rate of $28.14 \%$, therefore it has become the largest industry in Macao. The industrial structure of a single trend is also becoming more and more obvious in Macao with the growth of economy. This not only exacerbated the volatility of Macau's economy, but also brings the new challenges to the sustainable development of Macao economy (Macao economic association, 2006) [12].

\subsection{Single Source Structure, Serious Mainland}

Macau not only lacks of life resources and need to rely on the supply of mainland China; gambling industry development also needs mainland China as a strong backing. The Macau gambling industry's largest source is mainland tourists, followed by Hong Kong and Taiwan. The mainland has become the largest tourist market in Macao, followed by Hong Kong and Taiwan, since the "free walker" policy launched in 2003. As shown in Table 3 shows that entry passengers are increasing year by year, inbound tourist by 11,887.9 thousand person increased to 31,525.6 thousand person from 2003 to 2014; number of mainland China tourists is also a growing trend in general, the proportion of the total number of inbound tourists in Macao increased from $48.3 \%$ in 2003 to $67.41 \%$ in 2014, it is to see that the development of Macau's economy has been inseparable from the mainland China tourist market; The number of Hong Kong and Taiwan although decreased, but it also is the main tourist market of inbound tourists in Macao and the proportion is much higher than those of other European and American countries.

It is thus clear that Macao gambling industry tourist gradually inland in recent years. Chen Zhangxi, Zhang Xiaoping clearly put forward gambling tourist "mainland" concept for the first time, and points out that the greater the degree of "mainland", the risk of the Macau's economy will continue to increase; Macao's economy is difficult to find new economic support points once the mainland tourists' tourist destination changed; "Mainland” promotes gambling and tourism industry excessive reliance on the mainland market in Macao, and taking the demand for the mainland market as the basic guide; so it makes the resources to open up foreign markets

\begin{tabular}{|cc|} 
Table 2. Macao casino revenue over the years. \\
\hline Year & Casino revenue (million Macao dollars) \\
\hline 2003 & 30,315 \\
2004 & 43,511 \\
2005 & 47,134 \\
2006 & 57,521 \\
2007 & 83,847 \\
2008 & 109,826 \\
2009 & 120,383 \\
2010 & 189,588 \\
2011 & 269,058 \\
2012 & 305,235 \\
2013 & 361,866 \\
\hline
\end{tabular}

Data source: Macao statistics and Census Bureau. 
Table 3. The number of inbound tourists in Macao.

\begin{tabular}{|c|c|c|c|c|}
\hline Year & $\begin{array}{l}\text { Total number of inbound tourists } \\
\text { (Thousand person) }\end{array}$ & $\begin{array}{l}\text { Mainland China } \\
\text { (Thousand person) }\end{array}$ & $\begin{array}{c}\text { Hong Kong } \\
\text { (Thousand person) }\end{array}$ & $\begin{array}{c}\text { Taiwan } \\
\text { (Thousand person) }\end{array}$ \\
\hline 2003 & $11,887.9$ & $\begin{array}{c}5742 \\
(48.30 \%)\end{array}$ & $\begin{array}{c}4623.2 \\
(38.89 \%)\end{array}$ & $\begin{array}{c}1022.8 \\
(8.60 \%)\end{array}$ \\
\hline 2004 & $16,672.6$ & $\begin{array}{c}9529.7 \\
(57.16 \%)\end{array}$ & $\begin{array}{c}5051.1 \\
(30.30 \%)\end{array}$ & $\begin{array}{c}1286.9 \\
(7.72 \%)\end{array}$ \\
\hline 2005 & $18,711.2$ & $\begin{array}{c}10,463 \\
(55.92 \%)\end{array}$ & $\begin{array}{c}5614.9 \\
(30.01 \%)\end{array}$ & $\begin{array}{l}1482.5 \\
(7.92 \%)\end{array}$ \\
\hline 2006 & 21,998.1 & $\begin{array}{l}11,985.6 \\
(54.48 \%)\end{array}$ & $\begin{array}{c}6940.7 \\
(31.55 \%)\end{array}$ & $\begin{array}{c}1437.8 \\
(6.54 \%)\end{array}$ \\
\hline 2007 & $27,003.4$ & $\begin{array}{l}14,873.5 \\
(55.08 \%)\end{array}$ & $\begin{array}{c}8177 \\
(30.28 \%)\end{array}$ & $\begin{array}{c}1444.3 \\
(5.35 \%)\end{array}$ \\
\hline 2008 & $22,933.2$ & $\begin{array}{l}11,613.2 \\
(50.64 \%)\end{array}$ & $\begin{array}{c}7016.5 \\
(30.60 \%)\end{array}$ & $\begin{array}{c}1315.9 \\
(5.74 \%)\end{array}$ \\
\hline 2009 & $21,752.8$ & $\begin{array}{l}10,989.5 \\
(50.52 \%)\end{array}$ & $\begin{array}{c}6727.8 \\
(30.93 \%)\end{array}$ & $\begin{array}{c}1292.6 \\
(5.94 \%)\end{array}$ \\
\hline 2010 & $24,965.4$ & $\begin{array}{l}13,229.1 \\
(52.99 \%)\end{array}$ & $\begin{array}{c}7466.1 \\
(29.91 \%)\end{array}$ & $\begin{array}{c}1292.7 \\
(5.18 \%)\end{array}$ \\
\hline 2011 & $28,002.3$ & $\begin{array}{l}16,162.7 \\
(57.72 \%)\end{array}$ & $\begin{array}{c}7582.9 \\
(27.08 \%)\end{array}$ & $\begin{array}{c}1215.2 \\
(4.34 \%)\end{array}$ \\
\hline 2012 & $28,082.3$ & $\begin{array}{l}16,902.5 \\
(60.19 \%)\end{array}$ & $\begin{array}{c}7081.2 \\
(25.22 \%)\end{array}$ & $\begin{array}{c}1072.1 \\
(3.82 \%)\end{array}$ \\
\hline 2013 & $29,324.8$ & $\begin{array}{l}18,632.2 \\
(63.54 \%)\end{array}$ & $\begin{array}{c}6766 \\
(23.07 \%)\end{array}$ & $\begin{array}{c}1001.2 \\
(3.41 \%)\end{array}$ \\
\hline 2014 & $31,525.6$ & $\begin{array}{l}21,252.4 \\
(67.41 \%)\end{array}$ & $\begin{array}{c}6426.6 \\
(20.39 \%)\end{array}$ & $\begin{array}{c}953.8 \\
(3.03 \%)\end{array}$ \\
\hline
\end{tabular}

Data sources: Macao statistics and Census Bureau, figures in brackets are accounted for as a percentage.

continue to decline, and has been severely suppressed the process of economic diversification in Macao [13]. Fanny used statistical survey methods to analyze the shift of source markets "mainland" in Macau gambling tourism how impact on the development of Macau economy; He concluded that the mainland tourists are an important support market for the development of the Macao gambling, but the "mainland" will only enhance the vulnerability of Macao's gambling tourism industry [14].

\subsection{Strong Dependence on Foreign Capital}

\section{1) Gambling Industry Funds Root in External Funds, Strong Dependence on Foreign Capital}

Industrial structure simplification in Macao is the result of market choice in theory; it is similar to Finland, Sweden and other micro economies. But Finland and Sweden are based on local natural resources; they developed through technical innovation and industrial agglomeration and had local embeddedness. Macau's gambling is not relying on local natural resources, the development of its capital all are from the international capital, lack of local embeddedness, and rely on a special kind of institutional arrangement to maintain the development. To some extent, the single industrial structure of Macao is the result of institutional arrangement; it is not conducive to the rationalization and height of industrial structure. In general, the leading industry of an economy held by foreign capital, it is not only represents the vital spirit of the local economy control in the hands of foreign capital and brings risks to the local economic risks; with foreign capital holds the most profitable industry of Macau economy, then have much advantage in the competition of the local economy; It not only don't conducive to the growth of the local economy and will not form the upgrade conversion capability of economic structure; Instead, it inhibits the growth of local independent and endogenous economic factors, then forming the distribution structure is not conducive to the local and hindering the formation of sustainable development power. According to statistics and Table 4, we can know nearly $20 \%$ of Macao's gross domestic product is controlled by foreign capital. The gambling industry's capital come from international, which made the Macau gambling industry strongly depended on the foreign countries and caused the gambling industry upstream and downstream industry 
Table 4. Cumulative total foreign investment in Macao.

\begin{tabular}{ccc}
\hline Year & $\begin{array}{c}\text { Cumulative foreign investment } \\
\text { (million Macao dollars) }\end{array}$ & $\begin{array}{c}\text { Cumulative foreign investment of gambling industry } \\
\text { (million Macao dollars) }\end{array}$ \\
\hline 2002 & 25,876 & 15,106 \\
2003 & 28,481 & 16,602 \\
2004 & 31,169 & 182,35 \\
2005 & 40,269 & 24,376 \\
2006 & 53,134 & 34,791 \\
2007 & 73,326 & 49,087 \\
2008 & 84,077 & 58,211 \\
2009 & 84,052 & 54,343 \\
2010 & 109,036 & 70,280 \\
2011 & 119,263 & 68,176 \\
2012 & 151,278 & 87,565 \\
2013 & 189,376 & 114,765 \\
\hline
\end{tabular}

Data source: Macao statistics and Census Bureau.

chain is short; therefore, it is difficult to produce the related effect on the local economy, leading to the radiation effect is weak and the cooperation degree of industrial division of labor is not high.

Gambling industry as the leading industry in Macao, but very strong depended on international capital. The external dependence and high dependence of the economy of Macao will only strengthen and not weaken, when the main economic lifeline of Macao is control in international capital, this also will limit the formation of economic momentum in Macao. So far, there is no economy in the world which relies on foreign capital to cultivate their internal development factors and get a great success. International capital is not a charity, more not the seeder who cultivate internal independent growth gene of host country and area. In today's economic globalization, this feature is more prominent. Therefore, Macao's economy will be more go with the stream and the cultivation of endogenous growth factors will go farther and farther, if we treat the international capital as main dependence of the development of local economy.

2) Other Industries Strong Dependence on Foreign Capital

Not only the gambling industry strongly depends to foreign capital, most industry in Macau also depends on international capital and more serious. According to the data from the Macao statistics and Census Bureau, we can know that Macao has a total of 2430 foreign investment enterprises in 2013, and its total equity capital were 181 billon Macao dollars, which foreign capital was 149 billon Macao dollars (accounted for 82\% of total share capital). As shown in Table 5, according to the industry, the proportion of foreign capital in banking and securities industry was the highest (93\%), followed by wholesale and retail trade (90\%), hotel and catering industry (88\%); the proportion of foreign capital in the gambling industry was $68 \%$. The large proportion of foreign capital of Macao industry will greatly affect the stability of Macao's economy, and cannot cultivate local endogenous economic factors, thus depressing the independent development of local industries.

\subsection{The Competition Situation and the Future of the Gambling Industry}

The gambling industry as one of the senior level industry in Macao and leading industries in Macao, it is in an important position and its importance is self-evident. But with the legalization of gambling industry slowly open up, the gambling industry have to rise abruptly in all over the world; so Macao will face serious competition challenges and the development of the future is also a loss. Especially after the Macao gambling industry's success among the first in the world and far more than Las Vegas, casino in the surrounding area of Macao established one immediately after another, the Southeast Asia is also brewing open gambling and the only legal casino in Malaysia has been unable to meet the growing demand. We can see that the Kampuchea, Thailand border, 
Table 5. Corporate equity capital of industry foreign direct investment.

\begin{tabular}{cccc}
\hline & Total equity capital & Foreign capital & Proportion of foreign capital (\%) \\
\hline Total (million Macao dollars) & 18050 & 14883 & 82 \\
Gambling industry & 5989 & 4082 & 68 \\
Banking and securities industry & 8258 & 7676 & 93 \\
Industrial production & 1323 & 1032 & 78 \\
Transportation and storage and communication industry & 647 & 532 & 90 \\
Wholesale and retail trade & 549 & 495 & 82 \\
insurance industry & 572 & 467 & 88 \\
\hline
\end{tabular}

Data source: Macao statistics and Census Bureau.

Singapore, South Korea has slowly open up the gambling industry; a new gambling industry is being formed. Although in the short term, these casinos cannot be compared with Macau casino, but in some places to promote the development of the gambling industry is also better than Macao. Such as Philippines where the local tax rates are lower than Macao, and telephone betting is allowed in certain places. So, the long-term development will certainly take away the part source of Macao. After all, the Macau is the only place can legally establish casino in China, if surrounding casino is rapidly developed, it will form a competitive situation with Macao and bring the crisis to the gambling industry.

Macao economy has strong depended on gambling industry; therefore, gambling industry as the leading industry in Macao and the economic pillars of Macao; only the continuous expansion of the development of the lottery industry can promote the development of the overall economy. But since 2014, Macao gambling revenue fell seriously because of China's anti-corruption campaign; Gambling revenue is 3515.21 billion Macao dollars in 2014 and it fell 2.6\% than 2013; it appeared full-year revenue fell for the first time and suffered negative growth since lottery industry was opened in 2002, of course the downward trend continued until 2015. Therefore, the development of Macau's economy is facing severe challenges and the industrial diversification trend which cannot be halted.

\section{Moderate-Diversified Development Strategy for Macao's Industrial Structure}

The issue that how to realize the moderate diversification of industrial structure was put forward by Guo Yongzhong in 2011; it was not only a major task confronted by Macao SAR Government, industrial circle and academic circle, but also has become a task for China's overall development strategy [15]. The relationship between Macao's industrial diversification and economic growth was analyzed by Ji Chunli and Zeng Zhonglu through adopting the method of Ridge Regression Analysis. The results indicated that there exists positive correlation between industrial relative diversification and economic growth, but industrial non-related diversification has negative effect on the economic growth [16]. Therefore, moderate diversification of Macao's industry is the normal status of sustainable development of Macao.

Macao is located on the west side of the Pearl River Estuary; north of the Pearl River Delta; east across the Ling Dingyang; with Hong Kong and across the sea; west on Modaomen; and opposite with Zhuhai City, Wan Chai, Hengqin. Macao is a micro economy area, whose land area only has 32.8 square kilometers; its land resources, and also other material resources are very scarce. Based on the analysis of the actual condition of Macao's geographical environment and economic environment, we can know that we cannot blindly pursue "large and complete" industrial structure when adjusting Macao's industrial structure, and at the same time, it is impractical and unnecessary to establish a completely sound industrial structure. However, the development of secondary industry aims at increasing the anti-risk capacity and driving force, which are worth learning to some extent. In the case of fully taking care of gambling industry, we need to find the exact supporting point for promoting economic development and take "the international service center" as the predominant direction; we also need to develop the secondary industry consciously and moderately, and make it be complementary with the ter- 
tiary industry reasonably. With the development of moderate diversification of Macao's industry, it needs to gradually cultivate the independent growth and innovation ability to make Macao get rid of the long-term highly-dependent economy and form an independent economy with endogenous growth momentum, so as to reach the target of maintaining Macao's existing economy characteristics and competitive advantage; it can also play the role of spreading risk, then promoting the formation of comprehensive impetus and enhancing the endogenous growth momentum for Macau economy, and at the same time, laying a solid foundation for Macao to become an international tourism comprehensive service center.

\subsection{Developing a Moderately-Diversified Economic Structure of "Pillar Industry Combination"}

Macao's miniature economy is being limited by these objective factors, such as economic scale, market and resources shortage. Diversified development shall be moderate rather than well-rounded and leading in everything based on the effective analysis of resource allocation. However, Macao's gaming industry does not have the characteristics of the leading industry in miniature economy in Finland, Switzerland, Sweden, Denmark and other countries. The leading industries in these micro economy areas are rooted in locally innovative assets and resources, with endogenous competitive power, and are equipped with various upstream and downstream industry chains; relatively speaking, they possessed the connotation of moderately diversified and could promote the development of other industries. However, gaming industry is a leading industry with very short industrial chain, which isn't rooted in locally asset and resource. As it is hard to stimulate and breed local "innovative assets", it is not a competitive industry established based on regional advantage.

Considering the actual comparative advantages and the industrial characteristics of gaming industry in Macao, there exist no basic economic conditions for the long-term sustainable development of the dominant gaming industry in Macao. Therefore, Macao's moderate diversification cannot just maintain the gaming industry moderate diversification alone. Only by allocating the limited resources to a few industries instead of developing a leading industry, so we can establish several major pillar industries for supporting development of economy (pillar industry combination). From a long-term development, gaming industry can be one of Macao's economic factors; however, which cannot become the decisive factor dominating the future development of Macao's economy. We can cultivate emerging industry (cultural and creative industries, exhibition industry) in Macao and gradually replace the current gaming industry as a new leading industry through moderate diversification of economy, then to form a pillar industry combined economy. Based on this, we can establish a moderately-diversified industrial structure.

\subsection{Promoting the Longitudinal Diversified Development of Gaming Industry to Inject New Elements and Vigor into the Overall Economy}

Macao's economy is virtually a tourism economy, which is the comparative advantage and inevitable result of the years of development history in Macao. Thus, Macao shall regard the implementation of tourism economy mode as the long-term development strategy to push gaming tourism industry towards longitudinal diversified development and inject new elements and vigor into the overall economy; for opening gaming industry in 2002, there were clear requirements for non-gaming elements in the contract for gaming management rights signed by the government and the gaming companies, which did not give much attention to these requirements due to high rollers and tremendous momentum of earnings and had always focused on the development of gaming industry. Now gaming industry is facing difficulties, Macau's economy is necessary to attract customers to the non-gaming direction and transfer the direction of development; therefore the longitudinal diversified development of gaming industry ought to one of the main strategy.

Based on the Chi-Square test of independence, the Vinnicombe pointed out that tourists can promote the diversified development of Macao's tourism economy by using multiple correspondence analysis [17]. Macao has seen a large number of tourism thanks to free traveling policy. The number of tourists in Macao has rising to a large degree. At present, there are 30 million tourists annually in Macao, with an average of nearly 82 thousand tourists coming in and going out of Macao every day. Macao shall capture the period of opening up gaming industry and promote the development of the industries closely related to tourism industry by using gaming industry, such as the development of hotel, commerce, meeting, exhibition, culture, entertainment and other nongaming tourism industries. 


\subsection{Promoting the Development of Cultural Creative Industry to Inject New Impetus into the Growth of Macao's Economy}

The development of Macao’s cultural creative industry can help to give a better play to its advantages during the "moderate diversification of industry" in Macao, and at the same time establish "creative economy" in the future to inject new impetus into the growth of Macao's economy and spread the unique local culture and image of Macao to the world.

From the long-term goal, for the cultural creation industry in Macao, the establishment of cross-regional collaboration shall be realized, which is helpful for improving the current situation of narrow local market and heavy burden of operating cost in Macao. Therefore, the development of Macao's local culture creation industry should be actively leveraging on external markets, and the cultural creation industry with higher potential can be developed through Guangdong-Hong Kong-Macau regional cooperation platform. The Guangdong-Hong KongMacau Cultural and Creative Garden in Hengqin has offered the preferential policy and measures of going and trying beforehand to Hong Kong and Macao Cultural Corporate Park, which aims at gradually form the demonstration and scale effect of cultural industry through integration of industrial chain and become a regional creative capital in Asia and even a world cultural creative center. In addition, Qianhai in Shenzhen city, Cuiheng in Zhongshan city and other places all take cultural creative industry as the key industry for development, which with huge development potential in the future. Macao shall master the opportunity for the establishment of regional cooperation, realize mutual compensation of advantages, improve the developmental level of the overall industries and promote the development of Macao's overall economy through cooperation among enterprises in Guangdong, Hong Kong and Macao.

\subsection{Reasonably Developing Convention and Exhibition Industry to Strengthen Macao' Attraction to the World}

In accordance with the Report for Research on Macao's Convention and Exhibition Industry Development released by Macao Association of Conference and Exhibition Industry in 2010, Macao's convention and exhibition industry formally stepped into the establishment period of primary market development after breaking away from the infancy stage in 2010. Convention and exhibition industry is a very important way for Macao to demonstrate itself to the global society and an important part for the moderate diversification of Macao’ industry and development of pillar industry combined economic structure. Meanwhile, it is also an essential part for create compound competitiveness in Macao. We can enhance Macau's attraction to the world through reasonably developing convention and exhibition industry.

In a mature market economy, market regulation is commonly realized through the industry association which is a non-government organization. On one hand, convention and exhibition industry can better supervise the development of convention and exhibition industry. The association for conference and exhibition can coordinate and manage exhibition enterprises by establishing industrial standards; and strengthen information communication and research to increase the transparency of exhibition market; in addition, improving the quality and standard of the personnel related to exhibition by providing professional talents training. On the other hand, the association for conference and exhibition provides attentive services for the enterprises participating in the exhibition, including providing technical support, cultivation and development exhibition and developing markets for exhibitions, and also enhance the communication among exhibition enterprises at home and abroad. Therefore, Macao shall bring the motivational effect of the association for conference and exhibition into full play and raise the public awareness of Macao’s convention and exhibition industry.

\subsection{Strengthening the Efforts for Supporting Micro, Small and Medium-Sized Enterprises and Bringing the Enthusiasm of Micro, Small and Medium-Sized Enterprises in Moderate Diversification of Industry into Full Play}

The major enterprises for moderate diversification of Macao's economy are local enterprises, especially for small and medium-sized enterprises, as it is an answer based on fact and a requirement of moderate diversification of economy. According to the statistics, the local small and medium-sized enterprises in Macao are the enterprise group which accounts for $99 \%$ of the total enterprises, with the widest industrial distribution and activity in all market space. In 2009, Piao Zhenzi put forward that small and medium-sized enterprises are the main 
force of the enterprises in Macao and have created a large amount of wealth for the society, which attract more than half of labor force. So, supporting the small and medium-sized enterprises can not only facilitate the development of Macao's economy, but also is related with the stability of the society [18]. From this, we can know that small and medium-sized enterprises are the important part of economic entity in Macao, which subjectively are the main part for diversification, endogenous growth momentum and social and economic stability in Macao.

Small and medium-sized enterprises are the major part of economic entity in Macao. During the development of moderate diversification and pillar industry combined economic structure, the small and medium-sized enterprises can be properly emerged or reduced but must be preserved and make them play a necessary role. Though large enterprises are strong in all aspects, small and medium-sized enterprises have their own advantages, which have competitive advantages and also play a decisive role in the social development. These enterprises have a vigorous vitality, many of which have unique operation model and local characteristics. Macao small and medium enterprises can promote the development of economic diversification from the following five aspects: firstly, segment market and promote the scale effect of industry by enterprises assembling; secondly, establishing special industry through differentiation to increase the competence for developing industries; thirdly, setting up a cooperative-coordinative alliance of small and medium-sized enterprises for sharing resource and expanding advantages. In addition, combining the related industries of the local enterprises and the enterprises in Pearl River Delta Area, improving the forward and backward linkage of industry; fourth, making full use of the new technology and Internet technology brought by the new global industrial revolution and conducting industrial innovation; finally, establish an association alliance for small and medium-sized enterprises in Macao and enhance the competitiveness of micro, small and medium-sized enterprises to participate in economic development and market competition.

\section{References}

[1] Xu, Y.M. (2009) Macao Economy: Achieving Moderate Diversification in Development. Social Science in Guangdong, No. 6, 23-27.

[2] Zuo, L.C. and Liu, J. (2009) Implementing Appropriate Diversification Strategy to Promote the Sustainable Development of Macao Economy. International Economics and Trade Research, No. 9, 39-42.

[3] Chen, E. and Huang, G.L. (2012) Discussion on the Industrial Structure and the Path of Industrial Moderate Diversification in Macao. Industrial Economic Review, No. 1, 95-103.

[4] Guo, X.D. and Liu, C.S. (2009) The Economic Driving Ability of the Gaming Industry in Macau and the Choice of Its Industrial Policy. International Economics and Trade Research, No. 8, 21-26.

[5] Zheng, H.F. (2010) A Comparative Study of the Economic Structure of Mini-Economies and Its Implication towards Macao. Asia-Pacific Economic Review, No. 3, 127-132.

[6] Yuan, C.P. and Liang, W. (2013) Promote the Sustainable Development of Macau's Economy through the Cooperation between Hengqin and Macao. Journal of South China Normal University (Social Science Edition), No. 4, 67-76+160.

[7] Feng, X.Y. (2008) Thinking on the Path of Economic Diversification in Macao-A New Perspective of Analysis. Social Science in Guangdong, No. 6, 79-86.

[8] Feng, B.Y. (2010) A Study on the Direction and Policy of the Moderate Economic Diversification in Macao. Economic Yearbook of Hong Kong and Macao, 344.

[9] Chen, X. (2012) A Study on the Path and Strategy of Economic Diversification in Macao. Thesis, Jinan University, Guangzhou.

[10] Hong, X.J. (2010) Analysis of China’s Industry Wage Gap Based on S Gini Coefficient. Statistical Research, No. 5, 18-24.

[11] Gao, Y. (2013) An Empirical Analysis of the Income Gap between Industries in China. Thesis, Southwestern University of Finance and Economics, Chengdu.

[12] Macau Economic Association (2006) Macao Industrial Structure Optimization and Industrial Diversification. Macau Economic Association, Macao.

[13] Chen, Z.X. and Zhang, X.P. (2010) A Study on the “Mainland” Trend of Macao’s Gambling Tourism Industry. Industrial Economic Review, No. 4, 78-84.

[14] Fanny, V.C.K. and Mccartney, G. (2005) Mapping Resident Perceptions of Gaming Impact. Journal of Travel Research, 44, 177-187. http://dx.doi.org/10.1177/0047287505278997

[15] Guo, Y.Z. (2011) The Dilemma of the Strategic Adjustment of Industrial Structure in Macao. Academic Research, 11, 
64-69.

[16] Ji, C.L. and Zeng, Z.L. (2015) Micro Economy Industry Diversification and Economic Growth: An Empirical Analysis Based on the Data of Macao Region. International Business, No. 2, 86-94.

[17] Vinnicombe, T. and Sou, J.P.U. (2014) Macao’s Economic Diversification: Mainland China Passenger Data Analysis of the Opinions. Journal of China Tourism Research, 10, 347-362. http://dx.doi.org/10.1080/19388160.2013.865573

[18] Piao, Z.Z. (2009) Regional Economic Development Strategy and Government Regulation in China: Retrospect and Prospect of Ten Years’ Return (Economic Volume). Macao Polytechnic Institute, Macao, 279. 